\title{
Lipid and metabolite correlation networks specific to clinical and biochemical covariate show differences associated with sexual dimorphism in a cohort of nonagenarians
}

\author{
Francesca Di Cesare $(\mathbb{D}$ - Leonardo Tenori $(\mathbb{D}$ - Gaia Meoni $(\mathbb{D})$ Anna Maria Gori $(\mathbb{D} \cdot$ \\ Rossella Marcucci $(\mathbb{D}) \cdot$ Betti Giusti $(\mathbb{D}) \cdot$ Raffaele Molino-Lova $(\mathbb{D}) \cdot$ Claudio Macchi $(\mathbb{D}$ - \\ Silvia Pancani $(\mathbb{D} \cdot$ Claudio Luchinat $(\mathbb{D} \cdot$ Edoardo Saccenti $(\mathbb{D})$
}

Received: 9 April 2021 / Accepted: 13 June 2021 / Published online: 29 July 2021

(C) The Author(s) 2021

\begin{abstract}
This study defines and estimates the metabolite-lipidic component association networks constructed from an array of 20 metabolites and 114 lipids identified and quantified via NMR spectroscopy in the serum of a cohort of 355 Italian nonagenarians and ultranonagenarian. Metabolite-lipid association networks were built for men and women and related to an array of 101 clinical and biochemical parameters, including the presence of diseases, bio-humoral parameters, familiarity diseases, drugs treatments, and risk factors. Different connectivity patterns were observed in lipids, branched chains amino acids, alanine, and ketone bodies, suggesting their association with the sex-related and
\end{abstract}

F. Di Cesare $\cdot$ L. Tenori $\cdot$ C. Luchinat

Magnetic Resonance Center (CERM), University of Florence, Sesto Fiorentino, Italy

L. Tenori $\cdot$ C. Luchinat

Department of Chemistry “Ugo Schiff”, University of Florence,

Sesto Fiorentino, Italy

G. Meoni

Giotto Biotech srl, Florence, Italy

A. M. Gori · R. Marcucci • B. Giusti · C. Macchi

Department of Experimental and Clinical Medicine, University of Florence, Florence, Italy sex-clinical condition-related intrinsic metabolic changes. Furthermore, our results demonstrate, using a holistic system biology approach, that the characterization of metabolic structures and their dynamic interconnections is a promising tool to shed light on the dimorphic pathophysiological mechanisms of aging at the molecular level.

Keywords Aging · Differential network analysis · Lipidomics · Metabolomics · Network inference · Nuclear magnetic resonance $\cdot$ Sexual dimorphism

A. M. Gori · R. Marcucci · B. Giusti Atherothrombotic Unit, Careggi University Hospital, Florence, Italy

R. Molino-Lova $\cdot$ C. Macchi $\cdot$ S. Pancani

IRCCS Fondazione Don Carlo Gnocchi, Florence, Italy

C. Luchinat

Consorzio Interuniversitario Risonanze Magnetiche di Metallo Proteine (CIRMMP), Sesto Fiorentino, Italy

E. Saccenti $(\bowtie)$

Laboratory of Systems and Synthetic Biology, Wageningen

University \& Research, Wageningen, the Netherlands

e-mail: edoardo.saccenti@wur.nl 


\section{Introduction}

Nonagenarian and centenarian people represent a considerable increasing fraction of the world population, concentrated, above all, in economically developed countries [1, 2]. In Europe, Italy and France hold the record for the number of living centenarians. According to a 2019 statistic, in Italy, $1 \%$ of the population is 90 years older or more, and between 2000 and 2019 the number of centenarians (85\% women) increased from 11000 to more than 14456, and the number of ultracentenarians (>105 years, 94\% women) increased $136 \%$, from 472 to 1112 [3].

Aging is associated with irreversible variations in biological, pathophysiological, and psychological dynamics [4-8]: these age-related changes result in a decline of cognitive, motor, and sensory functions and in an increase of susceptibility to disease and disease frequency, a poor quality of life, and increased mortality [9, 10], defining a clinically and biologically heterogeneous population.

Many different fundamental biological processes, such as inflammation, cellular and immune senescence, mitochondrial dysfunction, and reduced resistance to oxidative stress are the main mechanisms at the basis of the aging process [10]. The progressive decline of physiological functions reflects changes happening at the molecular, organelle, cell, tissue, and, finally, the whole organism level $[11,12]$. Although individually these biochemical and molecular alterations underlying these processes may have only a modest effect on aging, taken together they involve a complex network of biomolecular mechanisms acting across multiple organs and at different molecular levels [13].

Accumulation of molecular damage has been proposed to be among the mechanisms driving aging [14-16], and this may include not only oxidative stress and DNA mutations, but also errors in protein synthesis and byproducts of enzymatic reactions [17]. In this light, the use of high-throughput omics techniques, like genomics, transcriptomics, proteomics, and metabolomics, offers a great promise for the understanding of the mechanisms that underlie aging $[11,18,19]$. In particular, the analysis of metabolic signatures associated with age and the comprehensive characterizing and understanding of the structures, functions, and interactions between metabolites and lipidic components, can shed light on the potential mechanism that could influence aging and longevity.

Nuclear magnetic resonance (NMR)-based metabolomics offers the possibility to quantify and investigate hundreds of various metabolites, lipid fractions and subfractions [20-23], detectable in biofluids, providing a global image of the complex metabolic, biological and biophysical processes associated with health [10, 22, 24] and disease [23, 25-27].

Integrative analysis of NMR-based metabolomics data using systems biology approaches focusing on the interactions and relationships among biochemical molecules like protein and metabolites can offer a holistic representation of the metabolic structures, indispensable for the understanding of the molecular mechanism underlying aging $[28,29]$.

Networks and network analysis of blood metabolites, lipid fractions and sub-fractions association networks are fundamental tools to extract information on the status of a biological system since correlation among metabolites and lipids concentration profiles can be used to model and to infer, at least partially, the structure of the underlying biological network [30]. In addition, these network models can be linked to clinical information such as biochemical parameters, risk factors, comorbidities, allowing the analysis of the relationships existing between different network structures and patient clinical characteristics.

In this work, we take an integrative approach to investigate the associations between metabolite and lipoprotein/lipid networks and the range of clinical, biochemical, environmental, socio-demographic parameters collected on a cohort of 355 nonagenarians from the Italian Mugello study [31]. The goal of the present analysis is twofold: first, we wanted to understand the association between different networks' structures and sex, because of its relevance for gender medicine of aging [32, 33]; second, we wanted to explore the complex web of relationship existing between clinical parameters, risk factors, and comorbidities and blood metabolites and lipids association patterns.

\section{Material and methods}

\section{Study description}

Samples were collected from the participants in the Mugello study, an epidemiological survey conducted from January 2010 to December 2011 in the Mugello area (north-eastward of Florence, Tuscany, Italy, see Fig. 1) [31]. The original study comprised 356 subjects - of 
which 96 men (27\%) and 260 women (73\%), with an age range of 84-103 years and of 88-105 years and with mean age $92.6( \pm 3.4)$ and $93.2( \pm 3.2)$ years, respectively. All participants, at the time of the cross-sectional survey, were subjected, by a trained physician, to a series of home-based structured interviews and medical examinations regarding clinically relevant geriatric conditions. Blood samples were also collected to perform routine laboratory tests. We refer the reader to the original publication for more details on the study design and the protocols that have been followed [31].

\section{Overview of clinical variables}

For the analysis presented in this article, we selected a sub-set of $M=101$ clinical covariates which were grouped into 5 categories:

1. Diseases ( $m=20$, dichotomous variables: $0-1)$ : describing the existence of a specific medical condition, i.e., myocardial infarction, congestive heart failure, peripheral vascular disease, hemiplegia, hypertension, dyslipidemia, dementia, cerebrovascular disease, diabetes (with and without organ damage), cancer, leukemia, disability, elderly depression (evaluated using the 15-item Geriatric Depression Scale screening questionnaire validated for the geriatric population [34]), cognitive impairment (evaluated using the Mini-Mental State Examination validated questionnaire [35]) and motor impairment (evaluated using Short Physical Performance Battery and Time up and go questionnaires [36, 37]).

2. Familiarity diseases $(m=5$, dichotomous variables: $0-1)$ : describing the existence of familiarity for cardiovascular, respiratory, and cerebrovascular diseases, dementia, and cancer.

3. Drugs treatments ( $m=13$, dichotomous variables: 0$1)$ : indicating the presence of ongoing pharmacological treatment for diseases described above.

4. Risk factors $(m=12$, continuous and dichotomous variables) including socio-demographic variables (age, education, sleep alertness, civil status, living with and smoke habit) and physical parameters (Body Mass Index [38-40], Windsor index or systolic ankle pressure measured using Ankle-brachial index [41, 42], Physical activity scale for elderly score [43], Handrig index [44], Mediterranean Diet Score $[45,46])$.

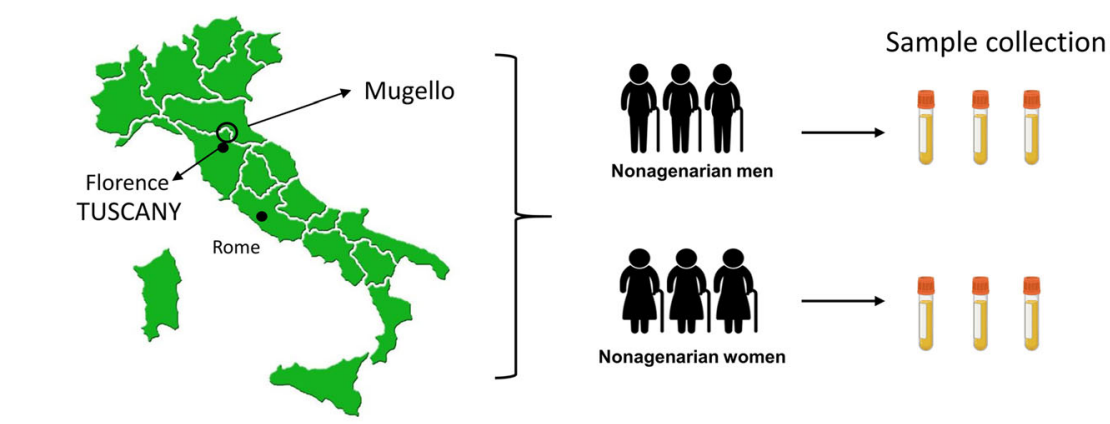

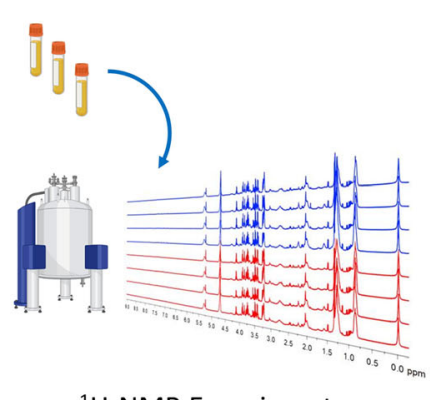

${ }^{1} \mathrm{H}-\mathrm{NMR}$ Experiments

Fig. 1 Graphical overview of the study and the data analysis strategy used in this study. Bio-humoral parameters refer to biochemical information such as blood count, mean cell volume, mean cell hemoglobin, thyroid hormones; see Table 1 for more details. Data are from the Mugello study [31] 
5. Bio-humoral parameters ( $m=51$ : continuous and dichotomous) including, i.e., complete blood count, mean cell volume, mean cell hemoglobin, thyroid hormones, cholesterol, HDL, LDL, and glycemia.

The variables considered and associated statistics are listed in Table 1.

\section{Ethical considerations}

The Mugello study [31] was conducted in agreement with the principles of the Helsinki Declaration on Clinical Research involving human beings (1964) and was approved by the Don Carlo Gnocchi Foundation Ethics Committee. Informed written consent was obtained from all participants or from their delegates before their inclusion in the original study.

Experimental methods

\section{Sample collection}

Blood samples were collected after overnight fasting, centrifuged at $2000 \mathrm{~g}$ for $10 \mathrm{~min}$ at $4^{\circ} \mathrm{C}$, and stored in aliquots at $-80^{\circ}$ until analyses, following standardized operating procedure as described in Bernini et al. [47].

\section{NMR experiments}

Serum samples were prepared for NMR analysis as described by Bernini et al. [47] and acquired using a Bruker $600 \mathrm{MHz}$ spectrometer (Bruker BioSpin s.r.l., Germany). NOESY 1D presat (one-dimensional NOESY) experiments were used to measure selectively low and high molecular weight molecules. Metabolites, lipoproteins, lipid fractions and sub-fractions were assigned, identified, and quantified using the AVANCE IVDr (Clinical Screening and In Vitro Diagnostics (IVD) research with B.I. Methods, Bruker BioSpin) [48], and the principal metabolites and main lipid fractions considered in this study are listed as follow: alanine, creatine, glutamic acid, glutamine, glycine, histidine, isoleucine, leucine, lysine, phenylalanine, proline, threonine, tyrosine, valine, acetic acid, citric acid, lactic acid, acetoacetic acid, pyruvic acid, glucose, main parameter (MP) triglycerides, main parameter (MP) cholesterol, main parameter (MP) LDL, main parameter (MP) HDL, main parameter (MP) Apo A1, main parameter (MP) Apo A2, and main parameter (MP) Apo B100.
A complete list of all lipid fractions and sub-fractions is presented in Supplementary Table S1.

Statistical methods

\section{Data pre-processing}

Only covariates with less than $25 \%$ missing data were considered; missing data were imputed using a Random Forest approach as implemented in $\mathrm{R}$ package missForest [49]; default parameters were used. All variables were log-transformed before analysis. One sample ("F_C_138") was excluded after a check of the spectra due to low quality shimming and remove from all subsequent analyses: the actual number of samples used in the present investigation is $n=355$.

Extraction of metabolic information related to clinical variables

For each blood metabolite and lipid fraction, we extracted the variation coming from a given clinical covariate, i.e., one of the $M=101$ covariates (see Table 1) recorded, using the method proposed by Bartzis et al. [50]. This approach extracts, from each metabolite/lipid, the part of concentration that is associated with a given covariate, thus implicitly adjusting for the remaining $M-1$ covariates. The rationale is that different metabolites/lipids sharing similar correlation/association with the same clinical covariable tend to be close to each other in the network, thus providing a better representation of the underlying biological phenomena [50].

Briefly, be $\mathrm{Y}^{(p)}$ the $(n \times 1)$ vector of concentrations of the $p$-th metabolite or lipid component (with $p=1,2, \ldots$, $P$ ) measured on $n=355$ subjects and be $\mathbf{X}$ the $(n \times M)$ matrix containing the $M=101$ clinical parameters (covariates) recorded on the $n$ subjects. Let be $\mathrm{X}_{m}$ the $n$ $\times 1$ vector containing the values for $m$-th clinical variables and $\mathrm{X}^{(-m)}=\left\{\mathrm{X}_{1}, \mathrm{X}_{2}, \ldots, \mathrm{X}_{M-1}\right\}$ the remaining $M$ -1 clinical variables. The information $\widehat{\mathrm{Y}}^{(p)}$ of a metabolite or lipid component $p$ associated with a specific clinical covariate $m$ was estimated by regressing $\mathrm{Y}^{(p)}$ on $\mathbf{X}$ and retaining only the main effects and first-order interactions of covariate $\mathrm{X}_{m}$ :

$\widehat{\mathrm{Y}}^{(p)}=\widehat{\beta}^{(p)} \mathrm{X}_{m}+\sum_{\delta \in \Delta} \widehat{\eta}_{\delta}^{(p)} \mathrm{X}_{m} \circ \prod_{j=1}^{M-1} \mathrm{X}_{j}^{\delta_{j}}$ 
Table 1 Descriptive statistics of clinical variables, divided into five separated categories, stratified by sex. For continuous variables the mean $\pm \mathrm{SD}$ (standard deviation) is reported. GDS geriatric depression scale, MMSE Mini-Mental State Examination, $S P P B$ short physical performance battery, $M C V$ mean corpuscular volume, $M C H$ mean corpuscular hemoglobin, $M C H C$ mean corpuscular hemoglobin concentration, $R D W C V$ red blood cells distribution width coefficient of variation, RDWSD red blood cells distribution width standard deviation, $P D W$ platelet distribution width, $M P V$ mean platelet volume, $P L C R$ platelet large cell ratio, GOT-AST aspartate aminotransferase, GPT-ALT alanine transaminase, $\gamma-G T$ gamma-glutamyl transferase, $T S H$ thyroid-stimulating hormone, WBCs white blood cells, RBCs red blood cells, HCT hematocrit, $H b A 1 C$ hemoglobin $\mathrm{A} 1 \mathrm{c}, C R P \mathrm{C}$-reactive protein, $A C E$ Angiotensin-converting enzyme, $A B I$ Ankle-Brachial Index, $B M I$ Body Mass Index, and MDS myelodysplastic syndromes

\begin{tabular}{|c|c|c|c|}
\hline & & women $(n=259,73.0 \%)$ & $\operatorname{men}(n=96,27.0 \%)$ \\
\hline \multirow[t]{20}{*}{ Diseases } & Myocardial infarction (\%) & 15.4 & 12.5 \\
\hline & Congestive heart failure $(\%)$ & 23.2 & 15.6 \\
\hline & Peripheral vascular diseases $(\%)$ & 22.4 & 11.5 \\
\hline & Hypertension (\%) & 55.9 & 58.3 \\
\hline & Dyslipidemia (\%) & 12.4 & 6.3 \\
\hline & Dementia (\%) & 13.5 & 13.5 \\
\hline & Diabetes $(\%)$ & 12.7 & 15.6 \\
\hline & Diabetes without organ damage $(\%)$ & 7.3 & 13.5 \\
\hline & Diabetes with organ damage $(\%)$ & 5.8 & 2.1 \\
\hline & Cancer $(\%)$ & 13.9 & 9.4 \\
\hline & Leukemia $(\%)$ & 0.4 & 0.0 \\
\hline & Disability (\%) & 62.6 & 88.5 \\
\hline & Motor impairment code & $9.0 \pm 6.7$ & $7.5 \pm 7.4$ \\
\hline & GDS code & $0.6 \pm 0.5$ & $1.8 \pm 0.8$ \\
\hline & Depression $(\%)$ & 58.7 & 77.1 \\
\hline & MMSE (\%) & 56.4 & 50.0 \\
\hline & SPPB $(\%)$ & 63.3 & 64.6 \\
\hline & Time up and go (\%) & 58.7 & 64.6 \\
\hline & Hemiplegia (\%) & 0.8 & 1.0 \\
\hline & Cerebrovascular diseases $(\%)$ & 21.8 & 20.8 \\
\hline \multirow[t]{19}{*}{ Bio-humoral parameters } & $\mathrm{MCV}(\mathrm{FL})$ & $90.4 \pm 5.3$ & $90.3 \pm 6.2$ \\
\hline & $\mathrm{MCH}$ (pg.) & $29.7 \pm 2.9$ & $29.7 \pm 2.6$ \\
\hline & $\mathrm{MCHC}(\mathrm{g} / \mathrm{dL})$ & $33.0 \pm 1.0$ & $33.0 \pm 1.1$ \\
\hline & RDWCV (fL) & $14.7 \pm 1.3$ & $14.8 \pm 1.4$ \\
\hline & RDWSD (fL) & $47.3 \pm 4.1$ & $47.5 \pm 5.8$ \\
\hline & PDW (fL) & $13.3 \pm 2.2$ & $13.9 \pm 2.5$ \\
\hline & MPV (fL) & $10.6 \pm 1.0$ & $10.9 \pm 1.0$ \\
\hline & PLCR & $29.6 \pm 6.9$ & $31.3 \pm 6.5$ \\
\hline & GOT-AST (IU/L) & $20.2 \pm 9.4$ & $20.1 \pm 5.9$ \\
\hline & GPT-ALT (IU/L) & $15.0 \pm 9.4$ & $14.2 \pm 5.2$ \\
\hline & $\gamma-\mathrm{GT}(\mathrm{IU} / \mathrm{L})$ & $25.2 \pm 27.6$ & $15.6 \pm 4.1$ \\
\hline & Neutrophil $\left(\times 10^{3} / \mu \mathrm{L}\right)$ & $4.0 \pm 2.7$ & $4.1 \pm 1.7$ \\
\hline & Lymphocyte $\left(\mathrm{x} 10^{3} / \mu \mathrm{L}\right)$ & $1.8 \pm 0.9$ & $1.8 \pm 0.7$ \\
\hline & Monocyte $\left(\times 10^{3} / \mu \mathrm{L}\right)$ & $0.5 \pm 0.2$ & $0.5 \pm 0.2$ \\
\hline & Eosinophil $\left(\times 10^{3} / \mu \mathrm{L}\right)$ & $0.2 \pm 0.1$ & $0.2 \pm 0.1$ \\
\hline & Basophil $\left(\times 10^{3} / \mu \mathrm{L}\right)$ & $0.02 \pm 0.02$ & $0.03 \pm 0.03$ \\
\hline & Neutrophyl - formula & $59.7 \pm 9.5$ & $60.7 \pm 9.7$ \\
\hline & Lymphocyte - formula & $28.9 \pm 8.8$ & $27.7 \pm 8.5$ \\
\hline & Monocyte - formula & $7.7 \pm 2.3$ & $7.9 \pm 2.4$ \\
\hline
\end{tabular}


Table 1 (continued)

\begin{tabular}{|c|c|c|c|}
\hline & & women $(n=259,73.0 \%)$ & men $(n=96,27.0 \%)$ \\
\hline & Eosinophil - formula & $3.2 \pm 2.1$ & $3.4 \pm 2.0$ \\
\hline & Basophil - formula & $0.4 \pm 0.4$ & $0.4 \pm 0.3$ \\
\hline & Creatinine $(\mathrm{mg} / \mathrm{dL})$ & $1.0 \pm 0.5$ & $1.1 \pm 0.7$ \\
\hline & Neutrophyl/lymphocyte & $0.5 \pm 0.3$ & $0.5 \pm 0.3$ \\
\hline & Platelets $\left(\mathrm{x} 10^{3} / \mu \mathrm{L}\right)$ & $219.6 \pm 93.9$ & $206.5 \pm 64.0$ \\
\hline & $\mathrm{Na}^{+}(\mathrm{mE} / \mathrm{ql})$ & $138.9 \pm 3.0$ & $138.6 \pm 2.9$ \\
\hline & $\mathrm{K}^{+}(\mathrm{mEql})$ & $4.3 \pm 0.5$ & $4.4 \pm 0.5$ \\
\hline & Cl- (mEql) & $101.7 \pm 7.8$ & $102.0 \pm 4.0$ \\
\hline & Total proteins $(\mathrm{g} / \mathrm{dL})$ & $6.4 \pm 0.6$ & $6.5 \pm 0.7$ \\
\hline & Albumin (g/dL) & $56.2 \pm 4.6$ & $56.1 \pm 4.8$ \\
\hline & $\alpha 1-\mathrm{G}(\mathrm{g} / \mathrm{dL})$ & $3.9 \pm 1.3$ & $4.0 \pm 1.5$ \\
\hline & $\alpha 2-\mathrm{G}(\mathrm{g} / \mathrm{dL})$ & $12.0 \pm 2.0$ & $12.0 \pm 1.8$ \\
\hline & $\beta-G(g / d L)$ & $12.2 \pm 1.7$ & $12.3 \pm 1.9$ \\
\hline & $\gamma-\mathrm{G}(\mathrm{g} / \mathrm{dL})$ & $15.6 \pm 3.7$ & $15.6 \pm 4.1$ \\
\hline & $\mathrm{A} / \mathrm{G}$ & $1.3 \pm 0.3$ & $1.3 \pm 0.3$ \\
\hline & $\mathrm{T} 3(\mathrm{pg} / \mathrm{mL})$ & $2.8 \pm 0.5$ & $2.9 \pm 0.6$ \\
\hline & T4 (ng/dL) & $0.9 \pm 0.2$ & $0.9 \pm 0.3$ \\
\hline & $\mathrm{TSH}(\mu \mathrm{UI} / \mathrm{mL})$ & $2.3 \pm 6.3$ & $2.1 \pm 4.0$ \\
\hline & WBCs $\left(\times 10^{3} /(\mu \mathrm{L})\right.$ & $6.3 \pm 1.9$ & $6.7 \pm 2.1$ \\
\hline & RBCs $\left(\times 10^{6} /(\mu \mathrm{L})\right.$ & $4.3 \pm 0.6$ & $4.4 \pm 0.6$ \\
\hline & Hemoglobin (g/dL) & $12.9 \pm 1.5$ & $12.9 \pm 1.7$ \\
\hline & $\mathrm{HCT}(\%)$ & $38.9 \pm 4.8$ & $39.0 \pm 4.8$ \\
\hline & glycemia (mg/dL) & $94.6 \pm 26.7$ & $93.3 \pm 22.7$ \\
\hline & $\mathrm{HbA1C}(\mathrm{g} / \mathrm{Hb})$ & $5.6 \pm 0.8$ & $5.6 \pm 0.8$ \\
\hline & Total cholesterol (mg/dL) & $190.5 \pm 42.0$ & $192.9 \pm 41.2$ \\
\hline & Cholesterol (mg/dL) & $0.4 \pm 0.5$ & $0.4 \pm 0.5$ \\
\hline & HDL (mg/dL) & $57.4 \pm 16.4$ & $59.0 \pm 18.7$ \\
\hline & LDL (mg/dL) & $110.3 \pm 33.7$ & $111.0 \pm 32.8$ \\
\hline & Triglycerides (mg/dL) & $113.9 \pm 47.5$ & $115.1 \pm 55.1$ \\
\hline & CRP (mg/L) & $0.9 \pm 2.1$ & $1.2 \pm 2.8$ \\
\hline & CRP $(\%)$ & 54.4 & 64.6 \\
\hline & Inflammatory protein $(\mathrm{mg} / \mathrm{L})$ & $9.2 \pm 20.6$ & $11.9 \pm 27.5$ \\
\hline & Benzodiazepine (\%) & 15.4 & 18.8 \\
\hline \multirow[t]{11}{*}{ Drug treatment } & Antidepressant (\%) & 18.5 & 19.8 \\
\hline & Diuretics (\%) & 52.5 & 44.8 \\
\hline & Beta-blockers (\%) & 10.4 & 15.6 \\
\hline & $\mathrm{Ca}^{++}$channel blockers $(\%)$ & 19.7 & 16.7 \\
\hline & ACE inhibitors (\%) & 39.0 & 35.4 \\
\hline & Vasodilators nitrates (\%) & 24.3 & 21.9 \\
\hline & Oral anticoagulant (\%) & 6.2 & 5.2 \\
\hline & Heparin (\%) & 11.6 & 9.4 \\
\hline & Antiplatelet (\%) & 40.0 & 35.4 \\
\hline & Antihyperlipidemic (\%) & 9.3 & 5.2 \\
\hline & Insulin (\%) & 4.6 & 3.1 \\
\hline
\end{tabular}


Table 1 (continued)

\begin{tabular}{|c|c|c|c|}
\hline & & women $(n=259,73.0 \%)$ & $\operatorname{men}(n=96,27.0 \%)$ \\
\hline \multirow{13}{*}{ Risk factors } & Oral antidiabetics $(\%)$ & 9.3 & 12.5 \\
\hline & Age (years) & $93.2 \pm 3.2$ & $92.6 \pm 3.4$ \\
\hline & Civil status (\% of married person) & 95.8 & 97.9 \\
\hline & Living with (number of person) & $2.8 \pm 1.2$ & $2.6 \pm 1.2$ \\
\hline & Education (years) & $4.2 \pm 2.6$ & $4.3 \pm 2.6$ \\
\hline & Tobacco exposure $(\%)$ & 13.9 & 72.9 \\
\hline & Winsor index & $1.0 \pm 0.3$ & $1.1 \pm 0.3$ \\
\hline & ABI code > $1(\%)$ & 23.6 & 36.5 \\
\hline & Handrig index (kg) & $14.3 \pm 6.9$ & $15.8 \pm 7$ \\
\hline & Pase score $(\%)$ & 38.6 & 52.1 \\
\hline & Sleep-alertness $(\%)$ & 4.3 & 4.2 \\
\hline & $\operatorname{BMI}\left(\mathrm{kg} / \mathrm{m}^{2}\right)$ & $24.8 \pm 4.7$ & $25.1 \pm 3.4$ \\
\hline & MDS index & $34.0 \pm 3.9$ & $34.5 \pm 3.3$ \\
\hline
\end{tabular}

where $\sum_{\delta \in \Delta} \widehat{\eta}_{\delta}^{(p)} \mathrm{X}_{m} \circ \prod_{j=1}^{M-1} \mathrm{X}_{j}^{\delta_{j}}$ models all main effects and high-order interactions in terms of clinical variables.

For each clinical parameter $m$ the procedure is repeated for all $P$ metabolites and lipid component to obtain $M=101 n \times P$ data sets $\mathrm{Y}_{m}=\left\{\mathrm{Y}_{(1)}, \mathrm{Y}_{(2)}, \ldots\right.$, $\left.\mathrm{Y}_{(p)}\right\}$ containing the part of the measured metabolite and lipid concentrations associated with each one of the 101 clinical parameters.

Network analysis

\section{Network concepts}

We briefly review here some network concepts. A network is a graphical representation of the relationships between objects, called nodes [51]. In a biological network, the nodes are molecular components, like genes, proteins, or, like in this study, metabolites and lipid components. The (existence of a) relationship between two nodes (molecular components) is represented by an edge connecting the two nodes. The type of association among the molecular features can be diverse in nature: in a protein-protein interaction network, edges represent the existence of physical interaction between proteins; in a metabolite-metabolite association network in which two metabolites are connected if their concentration levels are correlated.

Mathematically, a network can be represented as an adjacency (also called connectivity) matrix $\mathbf{A}$ : the rows and columns of the $\mathbf{A}$ represent the nodes whereas the entries $a_{i j}$ represent edges. A network is said to be unweighted if the edges $a_{i j}$ describing the association between node $i$ and $j$ are either 1 or 0 :

$a_{i j}=\left\{\begin{array}{cc}1 & \text { if }(i, j) \text { are associated } \\ 0 & \text { otherwise }\end{array}\right.$

If the strength or magnitude of the relationship can be quantified, a weight can be given to the edge; then, the network is said to be weighted: in this case, the elements of a weighted adjacency matrix $\mathbf{A}$ are real numbers indicating the strength of the interaction, and can vary, for instance, in the $[-1,1]$ range if the correlation is used as an index for the association.

\section{Reconstruction of metabolite and lipid association networks}

The Probabilistic Context Likelihood of Relatedness (PCLRC) [52] algorithm was used to build metabolite and lipid association networks using Spearman correlation as a measure of association [53]. The algorithm allows robust estimation of correlation employing a resampling strategy in combination with a modified version of the Context Likelihood of Relatedness (CLR) [54] to remove non-significant background correlations. The algorithm returns a probability matrix $\mathbf{P}$ with values between 0 and 1 that was used to filter significant correlation $r_{i j}$ between pairs of metabolites /lipids. In particular 
$r_{i j}=\left\{\begin{array}{cl}r_{i j} & \text { if } p_{i j} \geq 0.90 \\ 0 & \text { if } p_{i j}<0.90\end{array}\right.$

We built a metabolite/lipids association network for each of the $101 n_{1} \times P$ (for women) and $n_{2} \times P$ (for men) data sets $\mathrm{Y}_{m}=\left\{\mathrm{Y}_{(1)}, \mathrm{Y}_{(2)}, \ldots, \mathrm{Y}_{(p)}\right\}$ containing the part of the measured metabolite and lipid concentrations associated with each one of the 101 clinical parameters. We analyzed data for males and females separately, obtaining a total of 202 metabolite/lipids association networks that were divided into 5 categories $(S=$ diseases, bio-humoral parameters, familiarity diseases, risk factors, and drug treatments).

\section{Network differential connectivity analysis}

Each node in a network can be characterized using measures that can be derived from the patterns of its association. A very common measure is the node degree or connectivity $[55,56]$, that is the number of its connection. For a $p \times p$ network $\mathbf{A}$, the connectivity of the node $i$ is given by:

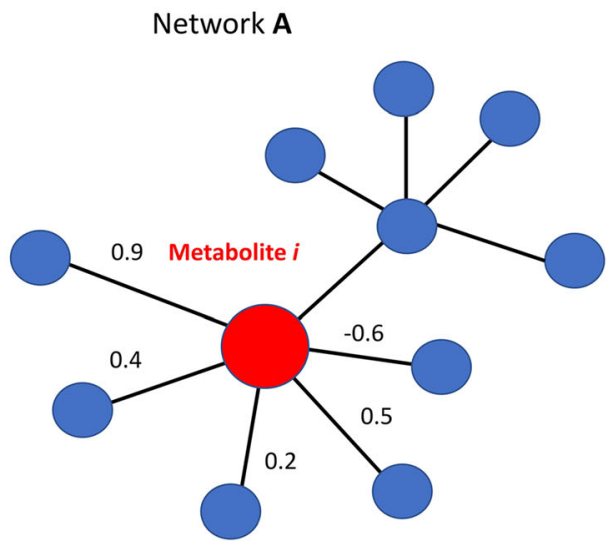

Connectivity of metabolite $i$ in Network $\mathbf{A}$

$\chi_{i}^{A}=0.9+0.4+0.2+0.5+|-0.6|=2.6$ $\chi_{i}=\sum_{j>i}\left|a_{i j}\right|$

Given a network A, the connectivity $\chi_{i}^{A}$ for metabolite/lipid $\mathrm{i}$ is defined as

$\chi_{i}^{A}=\left(\sum_{j=1}^{J}\left|r_{i j}\right|\right)-1$

If the network is unweighted, it holds $0<\chi_{i}<p-1$. If the network is weighted, the range of the connectivity depends on the nature of the association measure. If the absolute value of the correlation is used, like in this study, $\chi_{i}$ still ranges between 0 and $p-1$, in which case, it means that the molecular feature represented by node ai is perfectly correlated with all other nodes in the network.

Two networks A and $\mathbf{B}$ associated with two different conditions or groups (such as those built from men and women samples, or from samples from case-control patients) can be compared, implementing a so-called differential network analysis $[28,57]$.

The differential connectivity $\left(\Delta_{i}^{A, B}\right)$ of a metabolite/ lipid $i$ between two networks $\mathrm{A}$ and $\mathrm{B}$ is defined as

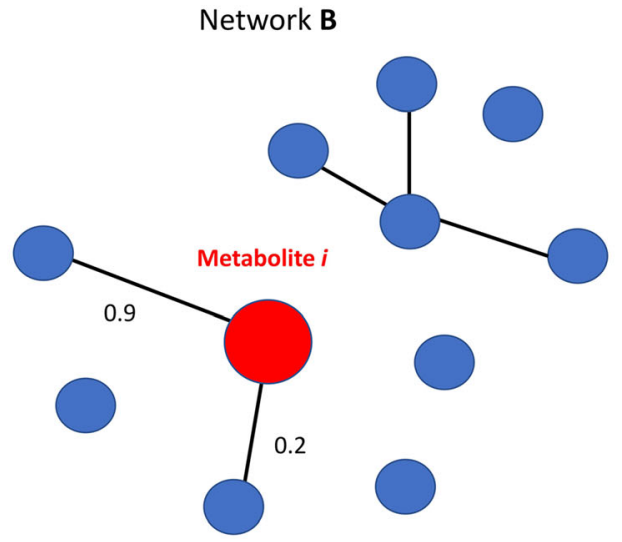

Connectivity of metabolite $i$ in Network B

$$
\chi_{i}^{B}=0.9+0.2=1.1
$$

Differential Connectivity of metabolite $i$

$$
\Delta \chi_{i}=\left|\chi_{i}^{A}-\chi_{i}^{B}\right|=2.6-1.1=1.5
$$

Fig. 2 Graphical illustration of the concept of node connectivity and differential connectivity used in this study. Each node represents a molecular feature (metabolite, lipid). The edge connecting two nodes represent the esistence of an association between two nodes, in this case expressed by correlation; the weight of the edge is given by the (absolute value) of the correlation. Figure adapted from [53] 


$$
\Delta_{i}^{A, B}=\chi_{i}^{A}-\chi_{i}^{B}
$$

The concept of differential connectivity is exemplified in Fig. 2.

\section{Estimation of the statistical significance of differential network connectivity}

The statistical significance of the differential connectivity $\left(\Delta_{i, k}^{A, B}\right)$, was assessed by means of a permutation-test. Briefly, the columns of every $\mathrm{Y}_{m}$ matrix are independently permuted to obtain a permutated matrix $\mathbf{X}_{(k)}$ whose column mean and variance are unchanged but the association between the elements of different columns is destroyed.

For each metabolite/lipid the differential connectivity was calculated for networks $a$ and $b$ built from the permuted data:

$\Delta_{i, k}^{A, B}=\chi_{i, k}^{A}-\chi_{i, k}^{B}$

and the overall procedure was repeated $k=100$ times to create a null distribution $D_{i}$ of permutated differential connectivity values. The significance of a given differential connectivity value $\Delta_{i}^{A, B}$ (calculated on the original data) was calculated as a $P$-value using the following formula (\#() indicates the number of elements):

$P$-value $=\frac{1+\#\left(\left|D_{i}\right|>\left|\Delta_{i}^{A, B}\right|\right)}{k}$

\section{Multivariate analysis of association networks}

Covariance simultaneous component analysis (COVSCA) [58] was performed to analyze simultaneously the (dis)similarities of the sets of $K=101$ metabolite and lipid association networks. The $\mathrm{K}$ association matrices are modeled as the number of lowdimensional prototypes $(L<<\mathrm{K})$ :

$$
\mathbf{S}_{k} \cong \sum_{l=1}^{L} c_{k l} \mathbf{Z}_{l} \mathbf{Z}_{l}^{T}
$$

where $c_{k l} \geq 0(1=1,2, \ldots, L)$ are weight coefficients and $\mathbf{Z}_{l} \mathbf{Z}_{l}^{T}$ are the prototypical covariance matrices that characterize the loadings set $\mathbf{Z}$ of dimension $J \times R_{l}$ that hold together for all $C_{k}$.

The COVSCA model was fitted separately for both women's and men's data with 3 rank-1 prototype matrices $(R=3)$ as the best compromise between the goodness-of-fit ( $82.7 \%$ ) and model complexity.

In COVSCA, each network becomes a point in an $R$ dimensional space and thus the method provides a methodology to represent and visualize a large number of networks in a way akin to standard principal component analysis: points (i.e., metabolite-lipid association networks) close in the R-dimensional space share similar characteristics, i.e., similar patterns of correlation among lipids and metabolites. The relative importance of each metabolite/lipid in shaping the observed network differences is given by the loadings that can also be interpreted in a PCA fashion.

\section{Clustering}

T-distributed stochastic neighbor embedding (t-SNE) [59] was applied on the 3-dimensional COVSCA scores to visualize detectable similarities and clusters among the networks.

\section{Software}

Calculations were performed using MATLAB (version 2018b R 9.5.0.9) an R (version 3.3.2). The $\mathrm{R}$ code for the PCLRC algorithm and the code to perform differential connectivity analysis are available at the link: www. $\underline{\text { semantics.systemsbiology.nl under the SOFTWARE tab. }}$

\section{Results and discussion}

Sex-specific differences of metabolite-lipid association networks

Metabolites and lipidic components take part in many metabolic processes; association networks, that quantify and visualize the interrelationships between molecular features, are representations of the complex web of biochemical reactions and pathways underlying the functioning of an organism: changes in the network structure can be considered to mirror alterations or remodulation of the underlying network of metabolic reactions [28]. The sex-specific serum metabolite-lipid component association networks were built using separately samples from nonagenarian women $\left(n_{1}=259\right)$ and men $\left(n_{2}=96\right)$, to avoid confounding due to sex. Previous results obtained on this study cohort have observed sexassociated differences between men and women 


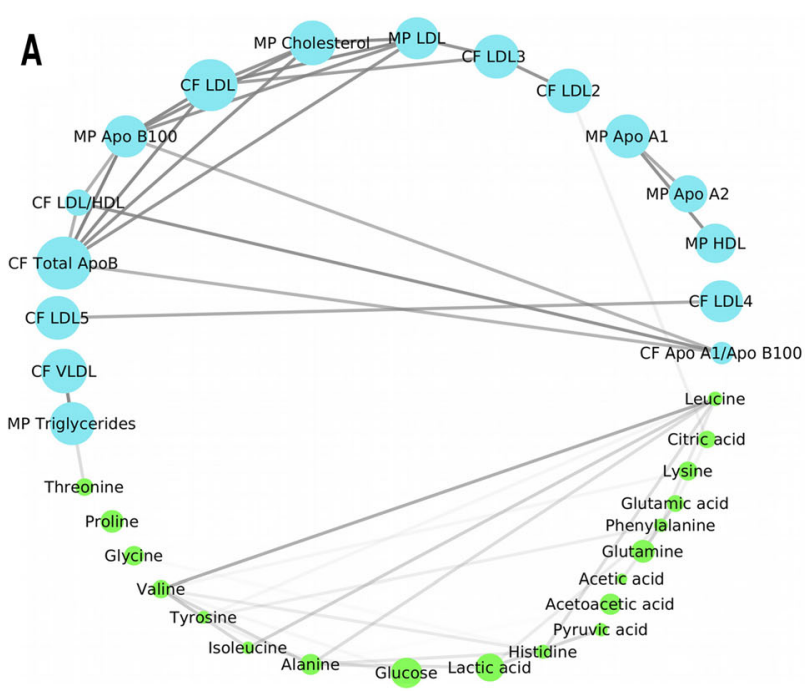

Fig. 3 Metabolite-lipid association networks for women (A) and men (B). Nodes are colored according to compounds' classification groups, light blue for lipid main parameters (MP) and calculated figures $(\mathrm{CF})$, and light green for metabolites. Edges represent

characteristics $[60,61]$. However, although the interplay between sex differences and age-related differences has not been explored fully, accumulating evidence of sex dimorphism in the disease susceptibility $[62,63]$ aging and longevity phenotypes $[64,65]$ suggests the necessity of analyzing separately men and women data.

The women- and men-specific networks have markedly different topology. The women-specific network (Fig. 3A) is more densely connected, for what concern metabolite-metabolite associations, with respect to the men-specific one (Fig. 3B). In both networks, lipidic components (lipoproteins, lipid fractions, and sub-fractions) have a strongly inter-connected structure although different lipid species are involved. We quantified and assessed the statistical differences of the metabolite-lipid association networks specific to men and women using node connectivity which quantifies the number and the strength of metabolite-lipid associations, thus representing the importance of given metabolite/ lipid in the network.

Differential network analysis results are given in Fig. 4. Seven out of 20 metabolites and 67 out of 114 lipoproteins and lipid fractions and sub-fractions have different connectivity patterns between men and women networks (adjusted $P$-value $\leq 0.05$ ). Among metabolites, only alanine, isoleucine, leucine, lysine, citric acid, acetoacetic acid, acetic acid, showed altered

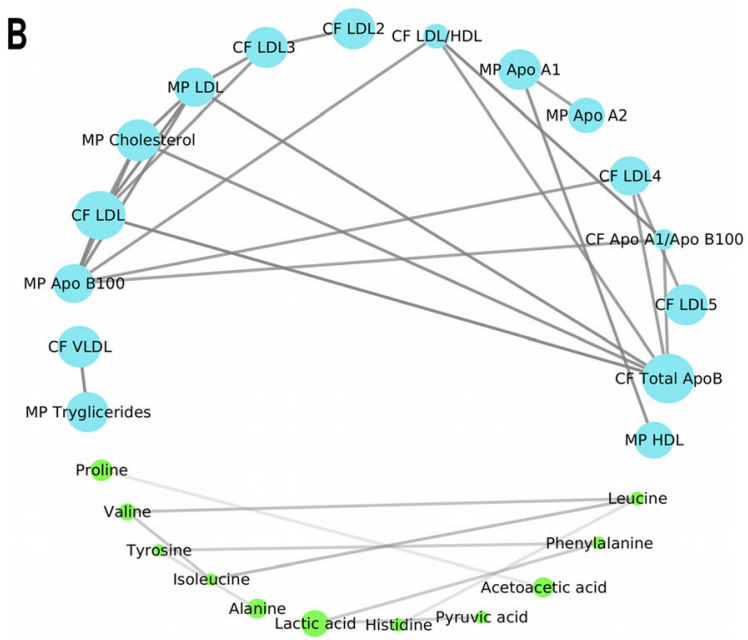

correlation with $|r| \geq 0.6$ and their width depends on the likelihood of the connections (see Eq. (3)). For sake of simplicity only metabolites, lipid main parameters, and calculated figures are shown

connectivity, indicating re-modulation of amino acids and ketone bodies' metabolism, a result consistent with other studies focusing on the networkbased analysis of the sex-specific difference in metabolite profiles in men and women [66-68]. In elderly women, re-modulation of amino acid metabolism results in a decreased level of branched amino acids (BCAAs) with respect to men [69, 70], and this phenomenon is associated with larger muscle mass loss, depending not only on a reduction in physical activity but also on a reduction of hormone activity, on an inadequate diet, and on the presence chronic diseases [69, 70]. Consistently with these observations, we found disruption of the association between alanine and leucine (present in women but not in the men network): leucine stimulates muscle protein synthesis [70-72] but is an important nitrogen donor for alanine biosynthesis [73].

Disruption of acetoacetic acid and acetic acid connectivity patterns suggests a re-modulation of ketone bodies' metabolism: acetic acid levels associate with prolonged fasting and diabetic ketosis, potentially frequent in elderly people with metabolic diseases [74], and, in women, with postmenopausal downregulation of gonadotropin which induces glycolytic dysregulation, resulting in a shift from physiological aerobic metabolism to a ketogenic phenotype $[75,76]$. 

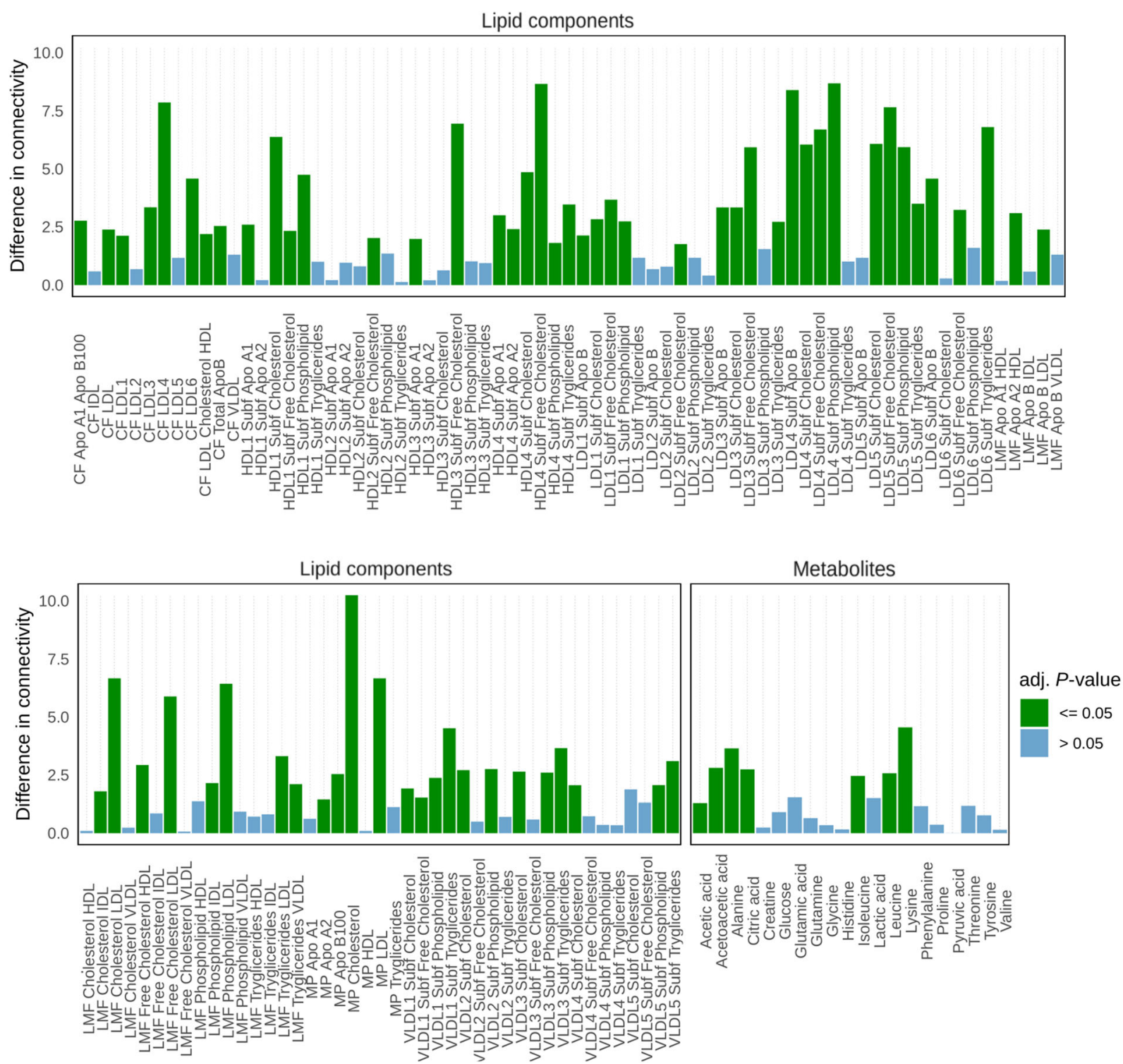

Fig. 4 Differential connectivity (Eq. (6); see Fig. 2 for an overview) from the differential network analysis of sex-related networks (men vs women) given in Fig. 3. For each metabolite and lipid component, adjusted $P$-values (Benjamini-Hochberg) are given.

Similarities and dissimilarities in different sex-related clinical variables-specific networks

We explored in a comprehensive way the relationships between metabolite-lipid association networks and the different 101 clinical covariates describing, for each subject, either the presence of a specific pathophysiological condition, familiarity diseases, pharmacological treatments, risk factors or the levels of 51 bio-humoral parameters (such as complete blood count, mean cell volume, hemoglobin, thyroid hormones. A complete list is reported in Table 1). For each of the 20 metabolites and 114 lipid fractions and sub-fractions, we first extracted the part of the observed variation of the concentration associated with a given clinical covariate (see Eq. (1)), and then we built association networks using only this fraction of the concentration, obtaining 101 (women) + 101 (men) different metabolite-lipid association networks. The rationale is that metabolites/lipids sharing similar relationships with a given covariate tend 


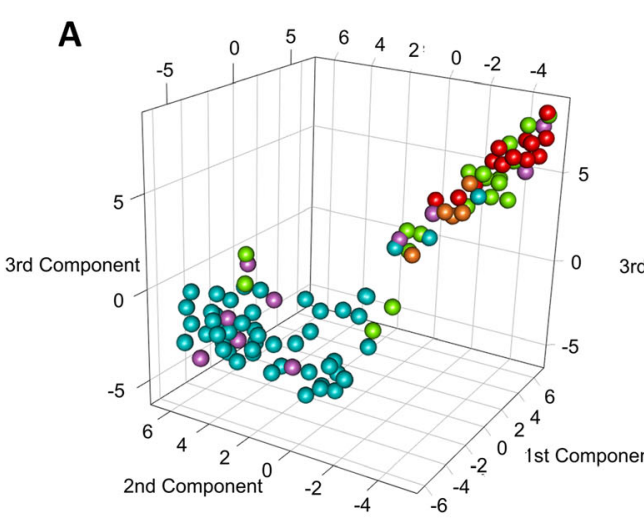

Fig. 5 Multivariate analysis of the metabolite-lipid association networks associated with the 101 clinical covariates (see Table 1) for women (A) and (B). The $101+101$ networks are analyzed using Covariance Simultaneous Component Analysis (see the "Multivariate analysis of association networks" section). Each sphere corresponds to a network and is coloured according to

to be close to each other in the network, and this can provide a clearer representation of the underlying biological phenomena.

Since is not practically possible to compare all 202 networks individually, we used a multivariate component method (COVSCA, see Methods) to model and visualize the (dis)similarity and the relationships among the networks in combination with clustering; results are shown for women in Fig. 5A and for men in Fig. 5B, where each dot represents a metabolite-lipid association network specific to a given covariate.

For both women and men, networks specific to biohumoral parameters separate from the networks specific to disease-related networks, indicating that the patterns of association among metabolites and lipid fractions and sub-fractions with these covariates are markedly different from those associated with comorbidity. Given a (clinical/biochemical) covariate, the statistical procedure employed can be seen as a correction procedure for confounders: in this light, the bio-humoral associated networks can be seen as representing metabolite/lipid relationship in a healthy condition. Networks associated with diseases tend to cluster with the networks related to ongoing pharmacological treatment of the same diseases suggesting the existence of oh shared information among these two groups of networks. Networks associated with risk factors (like age, smoking habits, and BMI) are scattered, indicating great heterogeneity and possibly reflecting that many risk scores are composite indexes summarizing both clinical and molecular features.
$-5$

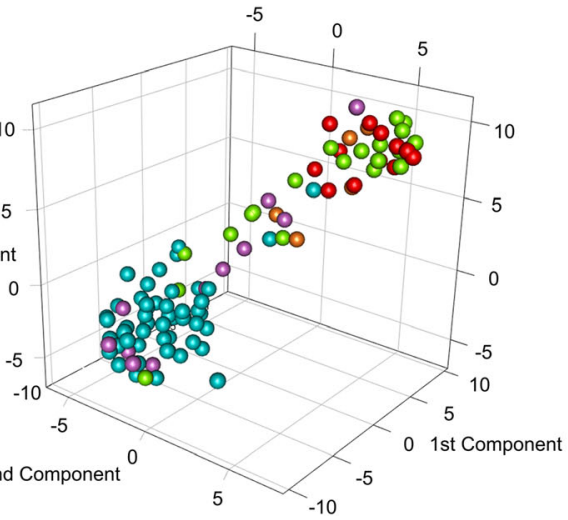

Diseases

O Bio-humoral parameters

- Drugs treatments

Familiarity diseases

Risk factors

the clinical variable-specific set: green colour corresponding to diseases, blue colour to bio-humoral parameters, red colour to drugs treatments, light brown colour to familiarity diseases and light violet colour to risk factors. Clustering is performed on the COVSCA score using t-SNE. Metabolite and lipid importance are given in Fig. 6

The relative importance of metabolites and lipidic components to explain the network clustering shown in Fig. 5A and $\mathrm{B}$ are given in Fig. 6A, B, and $\mathrm{C}$ for women and in Fig. 6D, E, F for men and can be interpreted as in standard principal component analysis (PCA). For both men and women, the first two components of the COVSCA model, explaining the variability within bio-humoral associated networks, are dominated LDL and VLDL lipid sub-fractions, while the third component, explaining the variability within diseaseassociated networks, is dominated by LDL and HDL. Our results show that different patterns of association between LDL and HDL fractions or interaction thereof are associated with comorbidity in this study cohort: LDL and HDL are not only associated with cardiovascular disease [77, 78], type II diabetes [79, 80], peripheral vascular disease [81, 82] and hypertension [83, 84] but also with dementia $[85,86]$ and cancer $[87,88]$ : the strong lipidic signature, suggest a potential different manifestation and response to health diseases in the elderly population $[89,90]$.

Overall, metabolites do not seem to play a significant role in shaping the observed difference among networks: only acetic acid, alanine, glutamine, and, less strongly, pyruvic acid have a relevant contribution to the model. Glucogenic amino acids (glutamine and alanine) have been associated with the regulation of aging and aging-related diseases [69]: in particular, altered levels of glutamine have been associated with higher intima-media thickness of carotid artery and, consequently, with coronary artery 


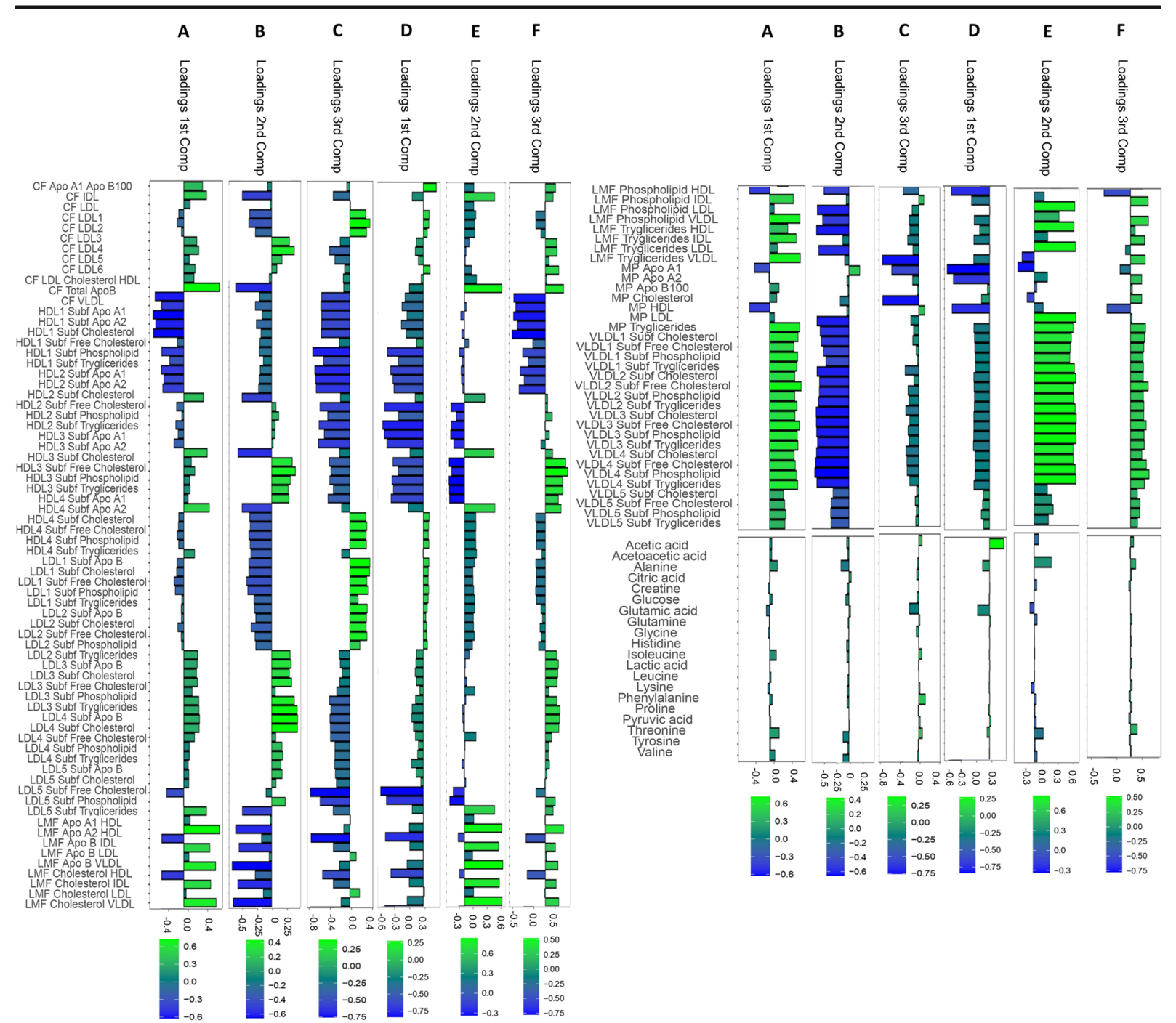

Fig. 6 Multivariate analysis of the metabolite-lipid association networks associated with the 101 clinical covariates (see Table 1) for women (A) and (B). The loadings give the importance of the metabolite and lipids to explain the patterns of network

(dis)similarity observed in Fig. 6. Panel A-C: loadings for the analysis of women networks (Fig. 5A); Panel D-F: loadings for the analysis of men networks (Fig. 5B)

atherosclerosis, causing cardio-vascular syndromes [91, 92], and could be responsible for the increase of the activity of the osteoclasts resulting in a reduction of the bone mineral density [93]. Alanine and acetic acids are correlated with protein-energy malnutrition in aged people [94], metabolic syndromes [95], and, in post-menopausal women, are correlated with a cellular ketogenic phenotypic change $[75,76]$.

Differential clinical networks analysis in nonagenarian women and men

Starting from the observation that the metabolite/lipids association networks associated with the same type of

covariate (bio-humoral parameters, diseases, drugs treatments, risk factors, and familiarity diseases) tend to share similar but not identical correlation patterns (see Fig. 7), we performed a pairwise comparison among the networks related to similar covariates. For each comparison, we recorded the significantly differentially connected metabolites ( $P$-value adjusted $\leq 0.05)$ and lipoproteins/ lipid fractions and sub-fractions (see Eq. (8)) for each comparison. We retained for further investigation only those molecular features that were found to be significant in more than $70 \%$ of the comparisons. Results are shown in Fig. 7. For both men and women bio-humoral 


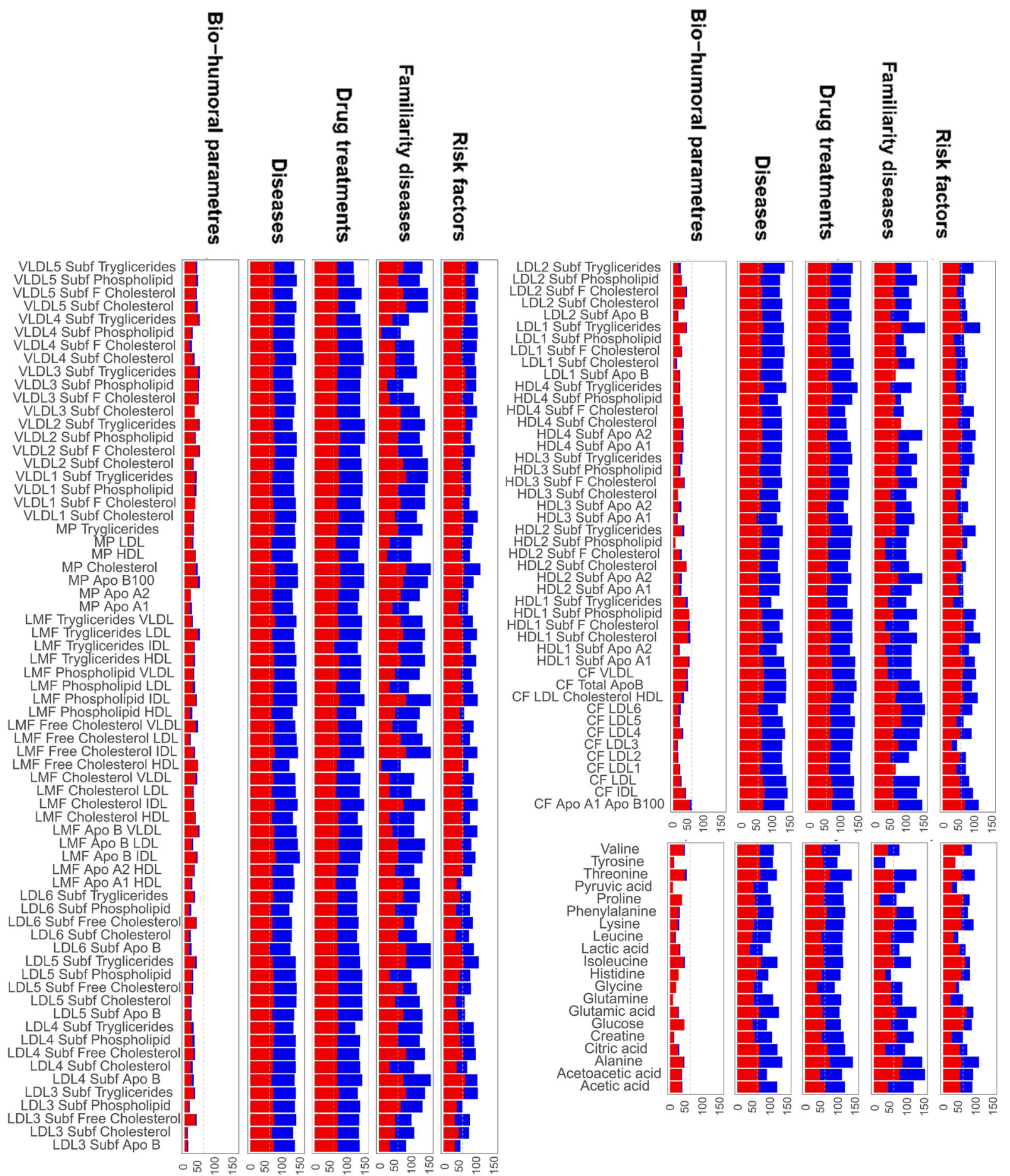

Fig. 7 Results of pairwise comparison of the $101+101$ networks associated with clinical the covariates. The percentage of time that a metabolite or lipid is found to be significantly differentially connected (adjusted $P$-value $<0.05$ ) between any two networks

belonging to the clinical covariate of the same type is shown. The (overlapping) red bars correspond to the women-related clinical variable-specific networks and blue bars correspond to the menrelated clinical variable-specific networks 

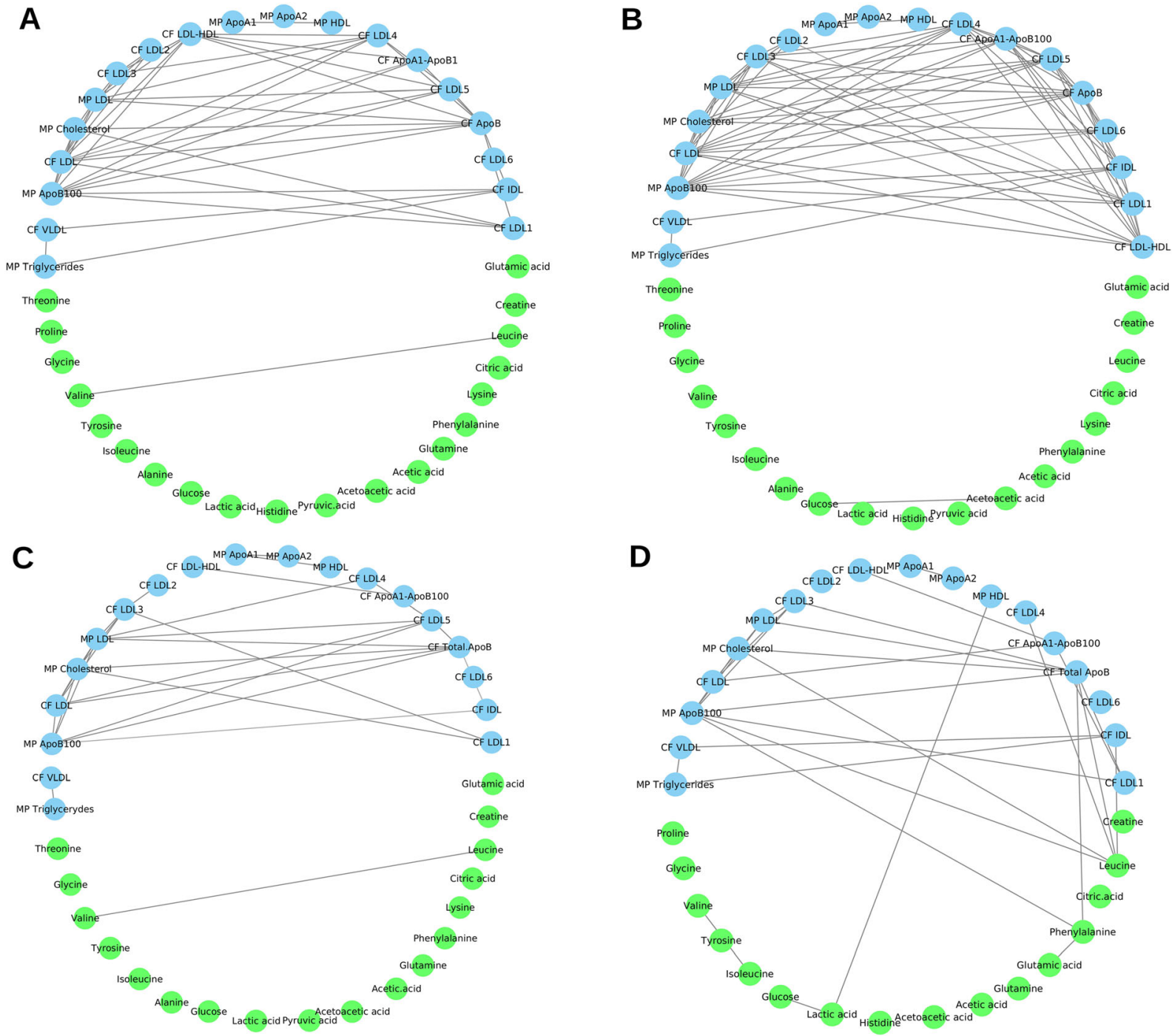

Fig. 8 Metabolite-lipid networks associated with peripheral vascular disease (A: women, B: men) and Diabetes (C: women, D: men). Nodes are colored according to compounds' classification groups, light blue color for lipid main parameters (MP) and calculated figures $(\mathrm{CF})$, and light green color for metabolites. Edges

represent correlation with $|r| \geq 0.6$ and their width depends on the likelihood of the connections. For sake of simplicity only metabolites, lipid main parameters (MP), and calculated figures (CF) are shown

parameter networks, we observe that very few metabolites and lipid features show different connectivity among different networks, indicating the similarity of these networks.

The comparison of disease-associated networks shows that for both men and women the full spectrum of (measured) lipids is associated with the differences among networks, suggesting their central role in pathophysiological mechanisms and in their resolutions; lipids are not only engaged in inter- and intra-cellular signaling regulation pathways but are also able to orchestrate inflammation

processes and to restore the homeostasis [96], which may explain also the strong lipid signature observed also in drug-treatment associated networks. In women risk factornetworks lipid components, in particular, VLDL, plays a major role: in post-menopausal women, VLDL is negatively associated with estrogens [97-99], and this is related to increased risk of cardiovascular diseases [100, 101], myocardial infarction [102], and hyperlipidemia [103]: its association with diverse risk factors is worthy of mention since VLDL is actually being reconsidered as a potential biomarker [78, 104, 105]. 
The role of metabolites in explaining network differences is more nuanced, and this probably reflects the large biochemical diversity of these molecules [106]. In diseases-specific networks, key differentiating metabolites are ketone bodies, BCAAs, threonine, and tyrosine (in women networks only), and alanine: this can reflect the association with particular diseases, such as type 1 and 2 diabetes mellitus [91, 107-110], sarcopenia [69, $71,72,111]$ and cognitive impairment $[112,113]$. Glutamine, glucose, proline, and BCAAs, increasing their metabolic activity, could be biomarkers to predict the emergence of neurodegenerative diseases [114], type 2 diabetes mellitus, and obesity conditions [91, 108, 109], and sarcopenia [69, 71, 72].

As an example, we show the networks associated with peripheral vascular disease and diabetes in both women and men (Fig. 8) which are two of the most common comorbidities among the subjects in this study (see Table 1).

When comparing the peripheral vascular disease association networks of women (Fig. 8A) and men (Fig. $8 \mathrm{~B})$, differential connectivity of leucine with lipidic components and among lipids component: while the latter has a strong association with peripheral vascular disease $[82,115]$, the remodulation of association between leucine and lipids suggests the existence an interplay between amino acids and lipids.

The difference in lipid correlation observed in diabetesspecific women (Fig. 8C) and men networks (Fig. 8D) further points to sex-specific differences in lipid metabolism [116, 117]. In particular, in women we observe a disruption of the correlation between acetic acids and glucose; it is known that acetic acid can lower glucose level, and can improve insulin resistance and metabolic abnormalities in the atherogenic prediabetic state [118]: the mechanism are not yet fully understood [119] and, as shown here, may be differentially regulated in men and women.

\section{Conclusions}

In this study, we presented a differential network analysis approach to highlight sex-related metabolic differences in cohort of nonagenarian subjects. Comparing the networks of nonagenarian women and men, we observed that lipids, branched chains amino acids, alanine, and ketone bodies show significant differences in connectivity in the two groups. In particular, we observed that lipids not only play a central role in the structural robustness of the network but also are directly associated with the intrinsic dynamic metabolic sex-related changes. The same approach was also applied to identify, in the disease-associated networks built in nonagenarian women and men, significantly differentially connected metabolites and lipoproteins/lipid fractions and sub-fractions. Our results show the importance of the lipid components in diseases, drug treatments, and familiarity disease, indicating their ability to participate in many pathophysiological mechanisms in nonagenarians; in the women's disease-specific networks, the rewiring of metabolic activity involves ketone bodies, branched chains amino acids, threonine, and tyrosine. In conclusion, this study provides information about the structure of sex-related networks in nonagenarians, contributing to elucidate the impact of gender on human physiology and pathophysiology in the elderly population and showcases how network analysis may provide a valuable tool in gender medicine.

Acknowledgements The authors acknowledge the support and the use of resources of Instruct-ERIC, a Landmark ESFRI project, and specifically the CERM/CIRMMP Italy Centre.

Author contribution A.M.G., R.M., B.G., R.M-L., C.M., and S.P. recruited patients, collected samples, and managed biological material and clinical data collection. G.M. obtained the NMR data. E.S., L.T., and F.D.C. performed data analyses. C.L., E.S., L.T., and F.D.C. interpreted the data and results, prepared the manuscript, and were responsible for its final content.

Data availability On requestSupplementary Information The online version contains supplementary material available at https://doi.org/10.1007/s11357-021-00404-3.

Code availability Code available upon request to E.S.Supplementary Information The online version contains supplementary material available at https://doi.org/10.1007 /s11357-021-00404-3.

\section{Declarations}

Ethics approval The study protocol was approved by the Ethical Committee of the Don Gnocchi Foundation.

Consent to participate Informed written consent was obtained from all participants or their legal representatives.

Consent for publication Patients signed informed consent regarding publishing their data. 
Conflict of interest The authors declare no competing interests.

\section{References}

1. Shrestha LB. Population Aging In Developing Countries. Health Aff (Millwood). 2000;19:204-12.

2. Suzman R, Beard JR, Boerma T, Chatterji S. Health in an ageing world-what do we know? Lancet. Elsevier. 2015;385:484-6.

3. I centenari in Italia. :5.n.d..

4. Campisi G, Chiappelli M, De Martinis M, Franco V, Ginaldi L, Guiglia R, et al. Pathophysiology of agerelated diseases. Immun Ageing A. 2009;6:12.

5. Pinquart $M$, Sörensen $S$. Influences of socioeconomic status, social network, and competence on subjective wellbeing in later life: a meta-analysis. Psychol Aging. 2000;15:187-224.

6. McLean AJ, Couteur DGL. Aging Biology and Geriatric Clinical Pharmacology. Pharmacol Rev. American Society for Pharmacology and Experimental Therapeutics. 2004;56:163-84.

7. Jazwinski SM, Kim S. Metabolic and Genetic Markers of Biological Age. Front Genet. Front. 2017;8.

8. Metz DH. Mobility of older people and their quality of life. Transp Policy. 2000;7:149-52.

9. Martin JE, Sheaff MT. The pathology of ageing: concepts and mechanisms. J Pathol. 2007;211:111-3.

10. Valenzuela JF, Monterola C, VJC T, Ng TP, Larbi A. Health and disease phenotyping in old age using a cluster network analysis. Sci Rep. Nature Publishing Group. 2017:7:15608.

11. Lorusso JS, Sviderskiy OA, Labunskyy VM. Emerging Omics Approaches in Aging Research. Antioxid Redox Signal. 2018;29:985-1002.

12. López-Otín C, Blasco MA, Partridge L, Serrano M, Kroemer G. The hallmarks of aging. Cell. 2013;153: 1194-217.

13. Kirkwood TBL. Systems biology of ageing and longevity. Philos Trans R Soc B Biol Sci Royal Society. 2011;366: 64-70.

14. Kirkwood TB, Austad SN. Why do we age? Nature. 2000;408:233-8.

15. Golubev A, Hanson AD, Gladyshev VN. Non-enzymatic molecular damage as a prototypic driver of aging. J Biol Chem. 2017;292:6029-38.

16. Yin D, Chen K. The essential mechanisms of aging: Irreparable damage accumulation of biochemical side-reactions. Exp Gerontol. 2005;40:455-65.

17. Gladyshev VN. The free radical theory of aging is dead. Long live the damage theory! Antioxid Redox Signal. 2014;20:727-31.

18. Valdes AM, Glass D, Spector TD. Omics technologies and the study of human ageing. Nat Rev Genet. Nature Publishing Group. 2013;14:601-7.

19. Zierer J, Menni C, Kastenmüller G, Spector TD. Integration of 'omics' data in aging research: from biomarkers to systems biology. Aging Cell. 2015;14:933-44.
20. Takis PG, Ghini V, Tenori L, Turano P, Luchinat C. Uniqueness of the NMR approach to metabolomics. TrAC Trends Anal Chem. 2019;120:115300.

21. Vignoli A, Ghini V, Meoni G, Licari C, Takis PG, Tenori L, et al. High-Throughput Metabolomics by 1D NMR. Angew Chem Int Ed. 2019;58:968-94.

22. Ghini V, Saccenti E, Tenori L, Assfalg M, Luchinat C. Allostasis and Resilience of the Human Individual Metabolic Phenotype. J Proteome Res. American Chemical Society. 2015;14:2951-62.

23. Vignoli A, Tenori L, Giusti B, Takis PG, Valente S, Carrabba N, et al. NMR-based metabolomics identifies patients at high risk of death within two years after acute myocardial infarction in the AMI-Florence II cohort. BMC Med. 2019;17:3.

24. Chen T, Cao Y, Zhang Y, Liu J, Bao Y, Wang C, et al. Random Forest in Clinical Metabolomics for Phenotypic Discrimination and Biomarker Selection. Evid Based Complement Alternat Med. Hindawi. 2013;2013:e298183.

25. Kim ER, Kwon HN, Nam H, Kim JJ, Park S, Kim Y-H. Urine-NMR metabolomics for screening of advanced colorectal adenoma and early stage colorectal cancer. Sci Rep. Nature Publishing Group. 2019;9:4786.

26. Meoni G, Lorini S, Monti M, Madia F, Corti G, Luchinat $\mathrm{C}$, et al. The metabolic fingerprints of $\mathrm{HCV}$ and $\mathrm{HBV}$ infections studied by Nuclear Magnetic Resonance Spectroscopy. Sci Rep. Nature Publishing Group. 2019;9: $1-13$.

27. Hart CD, Vignoli A, Tenori L, Uy GL, Van To T, Adebamowo C, et al. Serum Metabolomic Profiles Identify ER-Positive Early Breast Cancer Patients at Increased Risk of Disease Recurrence in a Multicenter Population. Clin Cancer Res Off J Am Assoc Cancer Res. 2017;23:1422-31.

28. Rosato A, Tenori L, Cascante M, De Atauri Carulla PR, dos Santos VAP M, Saccenti E. From correlation to causation: analysis of metabolomics data using systems biology approaches. Metabolomics. 2018;14:37.

29. Souza LPD, Alseekh S, Brotman Y, Fernie AR. Networkbased strategies in metabolomics data analysis and interpretation: from molecular networking to biological interpretation. Expert Rev Proteomics. Taylor \& Francis. 2020;17:243-55.

30. Camacho D, de la Fuente A, Mendes P. The origin of correlations in metabolomics data. Metabolomics. 2005;1: 53-63.

31. Molino Lova R, Sofi F, Pasquini G, Gori AM, Vannetti F, Abbate R, et al. The Mugello Study, a survey of nonagenarians living in Tuscany: Design, methods and participants' general characteristics. Eur J Intern Med. 2013;24: $745-9$.

32. Ostan R, Monti D, Gueresi P, Bussolotto M, Franceschi C, Baggio G. Gender, aging and longevity in humans: an update of an intriguing/neglected scenario paving the way to a gender-specific medicine. Clin Sci Lond Engl. 1979;2016(130):1711-25.

33. Almagro P, Ponce A, Komal S, Villaverde $\mathrm{M}$ de la A, Castrillo C, Grau G, et al. Multimorbidity gender patterns in hospitalized elderly patients. PLoS One. Public Library of Science. 2020;15:e0227252. 
34. Yesavage JA, Brink TL, Rose TL, Lum O, Huang V, Adey $\mathrm{M}$, et al. Development and validation of a geriatric depression screening scale: a preliminary report. J Psychiatr Res. 1982;17:37-49.

35. Folstein MF, Folstein SE, McHugh PR. "Mini-mental state": A practical method for grading the cognitive state of patients for the clinician. J Psychiatr Res. 1975;12:18998.

36. Treacy D, Hassett L. The Short Physical Performance Battery. Aust J Phys. 2017;64.

37. Beauchet O, Fantino B, Allali G, Muir S, Montero-Odasso $\mathrm{M}$, Annweiler C. Timed Up and Go test and risk of falls in older adults: A systematic review. J Nutr Health Aging. 2011;15:933-8.

38. Watson PE, Watson ID, Batt RD. Obesity indices. Am J Clin Nutr. 1979;32:736-7.

39. Manson JE, Stampfer MJ, Hennekens CH, Willett WC. Body Weight and Longevity: A Reassessment. JAMA. American Medical Association. 1987;257:353-8.

40. Schneider HJ, Friedrich N, Klotsche J, Pieper L, Nauck M, John U, et al. The Predictive Value of Different Measures of Obesity for Incident Cardiovascular Events and Mortality. J Clin Endocrinol Metab. Oxford Academic. 2010;95:1777-85.

41. Newman AB, Siscovick DS, Manolio TA, Polak J, Fried LP, Borhani NO, et al. Ankle-arm index as a marker of atherosclerosis in the Cardiovascular Health Study. Cardiovascular Heart Study (CHS) Collaborative Research Group. Circulation. 1993;88:837-45.

42. Victor A, Criqui MH, Pierre A, Allison MA, Creager MA, Curt D, et al. Measurement and Interpretation of the AnkleBrachial Index. Circulation. American Heart Association. 2012;126:2890-909.

43. Washburn RA, Smith KW, Jette AM, Janney CA. The physical activity scale for the elderly (PASE): Development and evaluation. J Clin Epidemiol. 1993;46: 153-62.

44. Amaral CA, TLM A, GTR M, MTL V, Portela MC. Hand grip strength: Reference values for adults and elderly people of Rio Branco, Acre, Brazil. PLoS One. Public Library of Science. 2019;14:e0211452.

45. Féart C, Samieri C, Rondeau V, Amieva H, Portet F, Dartigues J-F, et al. Adherence to a Mediterranean Diet, Cognitive Decline, and Risk of Dementia. JAMA. American Medical Association. 2009;302:638-48.

46. Panagiotakos DB, Pitsavos C, Stefanadis C. Dietary patterns: A Mediterranean diet score and its relation to clinical and biological markers of cardiovascular disease risk. Nutr Metab Cardiovasc Dis. 2006;16:559-68.

47. Bernini P, Bertini I, Luchinat C, Nincheri P, Staderini S, Turano P. Standard operating procedures for pre-analytical handling of blood and urine for metabolomic studies and biobanks. J Biomol NMR. 2011;49:231-43.

48. Jiménez B, Holmes E, Heude C, Tolson RF, Harvey N, Lodge SL, et al. Quantitative Lipoprotein Subclass and Low Molecular Weight Metabolite Analysis in Human Serum and Plasma by $1 \mathrm{H}$ NMR Spectroscopy in a Multilaboratory Trial. Anal Chem. 2018;90:11962-71.

49. Stekhoven DJ, Bühlmann P. MissForest—non-parametric missing value imputation for mixed-type data. Bioinformatics. Oxford Academic. 2012;28:112-8.
50. Bartzis G, Deelen J, Maia J, Ligterink W, Hilhorst HWM, Houwing-Duistermaat J-J, et al. Estimation of metabolite networks with regard to a specific covariable: applications to plant and human data. Metabolomics Off J Metabolomic Soc. 2017;13:129.

51. Pavlopoulos GA, Secrier M, Moschopoulos CN, Soldatos TG, Kossida S, Aerts J, et al. Using graph theory to analyze biological networks. BioData Min. 2011;4:10.

52. Suarez-Diez M, Saccenti E. Effects of Sample Size and Dimensionality on the Performance of Four Algorithms for Inference of Association Networks in Metabonomics. J Proteome Res. 2015;14:5119-30.

53. Jahagirdar S, Saccenti E. On the Use of Correlation and MI as a Measure of Metabolite-Metabolite Association for Network Differential Connectivity Analysis. Metabolites. Multidisciplinary Digital Publishing Institute. 2020;10: 171.

54. Akhand MAH, Nandi RN, Amran SM, Murase K. Context likelihood of relatedness with maximal information coefficient for Gene Regulatory Network inference. 2015 18th International Conference on Computer and Information Technology (ICCIT), 2015, pp. 312-316. https://doi. org/10.1109/ICCITechn.2015.7488088.

55. Lawyer G. Understanding the influence of all nodes in a network. Sci Rep. Nature Publishing Group. 2015;5:8665.

56. Wuchty S, Ravasz E, Barabási A-L. The Architecture of Biological Networks. In: Deisboeck TS, Kresh JY, curatori, editors. Complex Syst Sci Biomed. Boston, MA: Springer US; 2006. p. 165-81. https://doi.org/10.1007 /978-0-387-33532-2_5.

57. Ideker T, Krogan NJ. Differential network biology. Mol Syst Biol. John Wiley \& Sons, Ltd. 2012;8:565.

58. Smilde AK, Timmerman ME, Saccenti E, Jansen JJ, Hoefsloot HCJ. Covariances Simultaneous Component Analysis: a new method within a framework for modeling covariances. J Chemom. 2015;29:277-88.

59. van der Maaten L, Hinton G. Visualizing Data using tSNE. J Mach Learn Res. 2008;9:2579-605.

60. Padua L, Pasqualetti P, Coraci D, Imbimbo I, Giordani A, Loreti C, et al. Gender effect on well-being of the oldest old: a survey of nonagenarians living in Tuscany: the Mugello study. Neurol Sci Off J Ital Neurol Soc Ital Soc Clin Neurophysiol. 2018;39:509-17.

61. Giovannini S, Macchi C, Liperoti R, Laudisio A, Coraci D, Loreti C, et al. Association of Body Fat With HealthRelated Quality of Life and Depression in Nonagenarians: The Mugello Study. J Am Med Dir Assoc. 2019;20:564-8.

62. Sampathkumar NK, Bravo JI, Chen Y, Danthi PS, Donahue EK, Lai RW, et al. Widespread sex dimorphism in aging and age-related diseases. Hum Genet. 2020;139: $333-56$

63. Ober C, Loisel DA, Gilad Y. Sex-Specific Genetic Architecture of Human Disease. Nat Rev Genet. 2008;9: 911-22.

64. Gems D. Evolution of sexually dimorphic longevity in humans. Aging. 2014;6:84-91.

65. Regan JC, Partridge L. Gender and longevity: Why do men die earlier than women? Comparative and experimental evidence. Best Pract Res Clin Endocrinol Metab. 2013;27:467-79. 
66. Vignoli A, Tenori L, Luchinat C, Saccenti E. Age and Sex Effects on Plasma Metabolite Association Networks in Healthy Subjects. J Proteome Res. 2018;17:97-107.

67. Li Z, Zhang Y, Hu T, Likhodii S, Sun G, Zhai G, et al. Differential metabolomics analysis allows characterization of diversity of metabolite networks between males and females. PLoS One. Public Library of Science. 2018;13: $\mathrm{e} 0207775$.

68. Krumsiek J, Mittelstrass K, Do KT, Stückler F, Ried J, Adamski J, et al. Gender-specific pathway differences in the human serum metabolome. Metabolomics Off J Metabolomic Soc. 2015;11:1815-33.

69. Canfield C-A, Bradshaw PC. Amino acids in the regulation of aging and aging-related diseases. Transl Med Aging. 2019;3:70-89.

70. Fukagawa NK. Protein and amino acid supplementation in older humans. Amino Acids. 2013;44:1493-509.

71. Borack MS, Volpi E. Efficacy and Safety of Leucine Supplementation in the Elderly. J Nutr. 2016;146:2625S9S.

72. Hutson SM, Sweatt AJ, Lanoue KF. Branched-chain [corrected] amino acid metabolism: implications for establishing safe intakes. J Nutr. 2005;135:1557S-64S.

73. Haymond MW, Miles JM. Branched chain amino acids as a major source of alanine nitrogen in man. Diabetes. 1982;31:86-9.

74. Puchalska P, Crawford PA. Multi-dimensional roles of ketone bodies in fuel metabolism, signaling, and therapeutics. Cell Metab. 2017;25:262-84.

75. Rettberg JR, Yao J, Brinton RD. Estrogen: A master regulator of bioenergetic systems in the brain and body. Front Neuroendocrinol. 2014;35:8-30.

76. Brinton RD. Estrogen regulation of glucose metabolism and mitochondrial function: therapeutic implications for prevention of Alzheimer's disease. Adv Drug Deliv Rev. 2008;60:1504-11.

77. Gordon T, Kannel WB, Castelli WP, Dawber TR. Lipoproteins, Cardiovascular Disease, and Death: The Framingham Study. Arch Intern Med. 1981;141:1128-31.

78. Barter P, Gotto AM, LaRosa JC, Maroni J, Szarek M, Grundy SM, et al. HDL Cholesterol, Very Low Levels of LDL Cholesterol, and Cardiovascular Events. N Engl J Med. Massachusetts Medical Society. 2007;357:1301-10.

79. Krauss RM. Lipids and Lipoproteins in Patients With Type 2 Diabetes. Diabetes Care. American Diabetes Association. 2004;27:1496-504.

80. Vergès B. Lipid modification in type 2 diabetes: the role of LDL and HDL. Fundam Clin Pharmacol. 2009;23:681-5.

81. Bergmark C, Wu R, de Faire U, Lefvert AK, Swedenborg J. Patients With Early-Onset Peripheral Vascular Disease Have Increased Levels of Autoantibodies Against Oxidized LDL. Arterioscler Thromb Vasc Biol. American Heart Association. 1995;15:441-5.

82. Aday AW, Lawler PR, Cook NR, Ridker PM, Mora S, Pradhan AD. Lipoprotein Particle Profiles, Standard Lipids, and Peripheral Artery Disease Incidence. Circulation. American Heart Association. 2018;138: 2330-41.

83. Gil-Extremera B L. Disorders in Elderly Hypertensive Patients. Int J Hypertens. Hindawi. 2011;2012:e684515.
84. Onuh JO, Aliani M. Metabolomics profiling in hypertension and blood pressure regulation: a review. Clin Hypertens. 2020;26:23.

85. Reitz C, Tang M-X, Luchsinger J, Mayeux R. Relation of Plasma Lipids to Alzheimer Disease and Vascular Dementia. Arch Neurol. 2004;61:705-14.

86. Anstey KJ, Lipnicki DM, Low L-F. Cholesterol as a Risk Factor for Dementia and Cognitive Decline: A Systematic Review of Prospective Studies With Meta-Analysis. Am J Geriatr Psychiatry. 2008;16:343-54.

87. Borgquist S, Butt T, Almgren P, Shiffman D, Stocks T, Orho-Melander M, et al. Apolipoproteins, lipids and risk of cancer. Int J Cancer. 2016;138:2648-56.

88. Kökoğlu E, Karaarslan I, Mehmet Karaarslan H, Baloğlu H. Alterations of serum lipids and lipoproteins in breast cancer. Cancer Lett. 1994;82:175-8.

89. Johnson AA, Stolzing A. The role of lipid metabolism in aging, lifespan regulation, and age-related disease. Aging Cell. 2019; 18:e13048.

90. Gonzalez-Covarrubias V, Beekman M, Uh H-W, Dane A, Troost J, Paliukhovich I, et al. Lipidomics of familial longevity. Aging Cell. 2013;12:426-34.

91. Auro K, Joensuu A, Fischer K, Kettunen J, Salo P, Mattsson $\mathrm{H}$, et al. A metabolic view on menopause and ageing. Nat Commun. Nature Publishing Group. 2014;5: $1-11$.

92. Würtz P, Raiko JR, Magnussen CG, Soininen P, Kangas AJ, Tynkkynen T, et al. High-throughput quantification of circulating metabolites improves prediction of subclinical atherosclerosis. Eur Heart J. 2012;33:2307-16.

93. You Y-S, Lin C-Y, Liang H-J, Lee S-H, Tsai K-S, Chiou J$\mathrm{M}$, et al. Association between the metabolome and low bone mineral density in Taiwanese women determined by (1)H NMR spectroscopy. J Bone Miner Res Off J Am Soc Bone Miner Res. 2014;29:212-22

94. Polge A, Bancel E, Bellet H, Strubel D, Poirey S, Peray P, et al. Plasma amino acid concentrations in elderly patients with protein energy malnutrition. Age Ageing. 1997;26: 457-62.

95. Monnerie S, Comte B, Ziegler D, Morais JA, Pujos-Guillot E, Gaudreau P. Metabolomic and Lipidomic Signatures of Metabolic Syndrome and its Physiological Components in Adults: A Systematic Review. Sci Rep. Nature Publishing Group. 2020;10:1-13.

96. Chiurchiù V, Leuti A, Maccarrone M. Bioactive Lipids and Chronic Inflammation: Managing the Fire Within. Front Immunol. 2018;9.

97. Schaefer EJ, Foster DM, Zech LA, Lindgren FT, Brewer HB, Levy RI. The Effects of Estrogen Administration on Plasma Lipoprotein Metabolism in Premenopausal Females. J Clin Endocrinol Metab. Oxford Academic. 1983;57:262-7.

98. Palmisano BT, Zhu L, Stafford JM. Estrogens in the Regulation of Liver Lipid Metabolism. Adv Exp Med Biol. 2017;1043:227-56.

99. Mauvais-Jarvis F, Clegg DJ, Hevener AL. The role of estrogens in control of energy balance and glucose homeostasis. Endocr Rev. 2013;34:309-38.

100. Ference BA, Ginsberg HN, Graham I, Ray KK, Packard CJ, Bruckert E, et al. Low-density lipoproteins cause atherosclerotic cardiovascular disease. 1. Evidence from 
genetic, epidemiologic, and clinical studies. A consensus statement from the European Atherosclerosis Society Consensus Panel. Eur Heart J. 2017;38:2459-72.

101. Ivanova EA, Myasoedova VA, Melnichenko AA, Grechko AV, Orekhov AN. Small Dense Low-Density Lipoprotein as Biomarker for Atherosclerotic Diseases. Oxidative Med Cell Longev. 2017;2017:1273042.

102. Khan HA, Ekhzaimy A, Khan I, Sakharkar MK. Potential of lipoproteins as biomarkers in acute myocardial infarction. Anatol J Cardiol. 2017;18:68-74.

103. Streja D, Streja E. Management of Dyslipidemia in the Elderly. In: Feingold KR, Anawalt B, Boyce A, Chrousos G, Dungan K, Grossman A, et al., curatori. Endotext [Internet]. South Dartmouth (MA): MDText.com, Inc.; 2000 http://www.ncbi.nlm.nih.gov/books/NBK279133/

104. von Zychlinski A, Kleffmann T. Dissecting the proteome of lipoproteins: New biomarkers for cardiovascular diseases? Transl Proteomics. 2015;7:30-9.

105. Ren J, Grundy SM, Liu J, Wang W, Wang M, Sun J, et al. Long-term coronary heart disease risk associated with verylow-density lipoprotein cholesterol in Chinese: the results of a 15-Year Chinese Multi-Provincial Cohort Study (CMCS). Atherosclerosis. 2010;211:327-32.

106. Psychogios N, Hau DD, Peng J, Guo AC, Mandal R, Bouatra S, et al. The Human Serum Metabolome. PLoS One. Public Library of Science. 2011;6:e16957.

107. Nakayama H, Tokubuchi I, Wada N, Tsuruta M, Ohki T, Oshige $\mathrm{T}$, et al. Age-related changes in the diurnal variation of ketogenesis in patients with type 2 diabetes and relevance to hypoglycemic medications. Endocr J. 2015;62: 235-41.

108. Park S, Sadanala KC, Kim E-K. A Metabolomic Approach to Understanding the Metabolic Link between Obesity and Diabetes. Mol Cell. 2015;38:587-96.

109. Lo C-J, Tang H-Y, Huang C-Y, Lin C-M, Ho H-Y, Shiao $\mathrm{M}-\mathrm{S}$, et al. Metabolic Signature Differentiated Diabetes Mellitus from Lipid Disorder in Elderly Taiwanese. J Clin Med. 2018;8.

110. Garcia E, Shalaurova I, Matyus SP, Oskardmay DN, Otvos JD, Dullaart RPF, et al. Ketone Bodies Are Mildly Elevated in Subjects with Type 2 Diabetes Mellitus and Are Inversely Associated with Insulin Resistance as Measured by the Lipoprotein Insulin Resistance Index. J Clin Med. 2020;9.
111. Agostini D, Zeppa Donati S, Lucertini F, Annibalini G, Gervasi M, Ferri Marini C, Piccoli G, Stocchi V, Barbieri E, Sestili P. Muscle and Bone Health in Postmenopausal Women: Role of Protein and Vitamin D Supplementation Combined with Exercise Training. Nutrients. 2018;10(8): 1103.

112. van de Rest O, Bloemendaal M, de Heus R, Aarts E. Dosedependent effects of oral tyrosine administration on plasma tyrosine levels and cognition in aging. Nutrients. 2017;9(12):1279.

113. Ravaglia G, Forti P, Maioli F, Bianchi G, Martelli M, Talerico $\mathrm{T}$, et al. Plasma amino acid concentrations in patients with amnestic mild cognitive impairment or Alzheimer disease. Am J Clin Nutr. Oxford Academic. 2004;80:483-8.

114. Socha E, Koba M, Kośliński P. Amino acid profiling as a method of discovering biomarkers for diagnosis of neurodegenerative diseases. Amino Acids. 2019;51:367-71.

115. Kou M, Ding N, Ballew SH, Salameh MJ, Martin SS, Selvin E, et al. Conventional and Novel Lipid Measures and Risk of Peripheral Artery Disease. Arterioscler Thromb Vasc Biol. American Heart Association. 2021;41:1229-38.

116. Palmisano BT, Zhu L, Eckel RH, Stafford JM. Sex differences in lipid and lipoprotein metabolism. Mol Metab. 2018;15:45-55.

117. Varlamov O, Bethea CL, Roberts CT. Sex-Specific Differences in Lipid and Glucose Metabolism. Front Endocrinol. 2015;5.

118. Mitrou P, Petsiou E, Papakonstantinou E, Maratou E, Lambadiari V, Dimitriadis P, et al. The role of acetic acid on glucose uptake and blood flow rates in the skeletal muscle in humans with impaired glucose tolerance. Eur J Clin Nutr. 2015;69:734-9.

119. Santos HO, de Moraes WMAM, da Silva GAR, Prestes J, Schoenfeld BJ. Vinegar (acetic acid) intake on glucose metabolism: A narrative review. Clin Nutr. ESPEN. 2019;32:1-7.

Publisher's note Springer Nature remains neutral with regard to jurisdictional claims in published maps and institutional affiliations. 